\title{
Phase 1: The Case for 10,000-Year-0ld Agriculture at Kuk
}

\author{
Tim Denham, Jack Golson and Philip Hughes
}

Evidence of past human activities sealed by grey clay was first discovered during stratigraphic recording of plantation drains at Kuk in 1974. Excavations occurred at the site in subsequent years (1975-77 and 1998) to determine more fully the character of the finds (Fig. 11.1). The archaeological remains, which date to 10,000 years ago, are unique to Kuk and have two major components: a palaeochannel (a prehistoric channel) and a palaeosurface (an old buried land surface). These components are discussed below and interpreted with respect to associated land usage and whether they represent prehistoric agricultural practices.

\section{Palaeochannel}

The palaeochannel, referred to in the field as Kundil's Baret and by Denham (2003a) in his analytical work as channel 101, was recorded in the walls of Station drains and excavated in several trenches (Fig. 11.1). Based on these investigations, the course of the palaeochannel across the edge of the present-day wetland has been reconstructed. Channel 101 has some relatively straight and other slightly sinuous reaches.

The cross-section of the channel is slightly variable along its length, although generally it has a relatively broad bed with moderately sloping concave sides (Figs 11.2 and 11.3). The edges of the channel have slumped and been eroded while it was in use or before it filled in. The basal fill consists of an admixture of soil and subsoil granules and organic matter. The organic matter, which includes insects, leaves, seeds and wood, is well preserved, indicating that waterlogged conditions have persisted since deposition about 10,000 years ago (Fig. 11.4). Examination of these materials has enabled the local environment within and adjacent to the palaeochannel to be reconstructed (Denham et al. 2003; Denham, Haberle and Lentfer 2004; Denham, Sniderman et al. 2009; Haberle et al. 2012). 


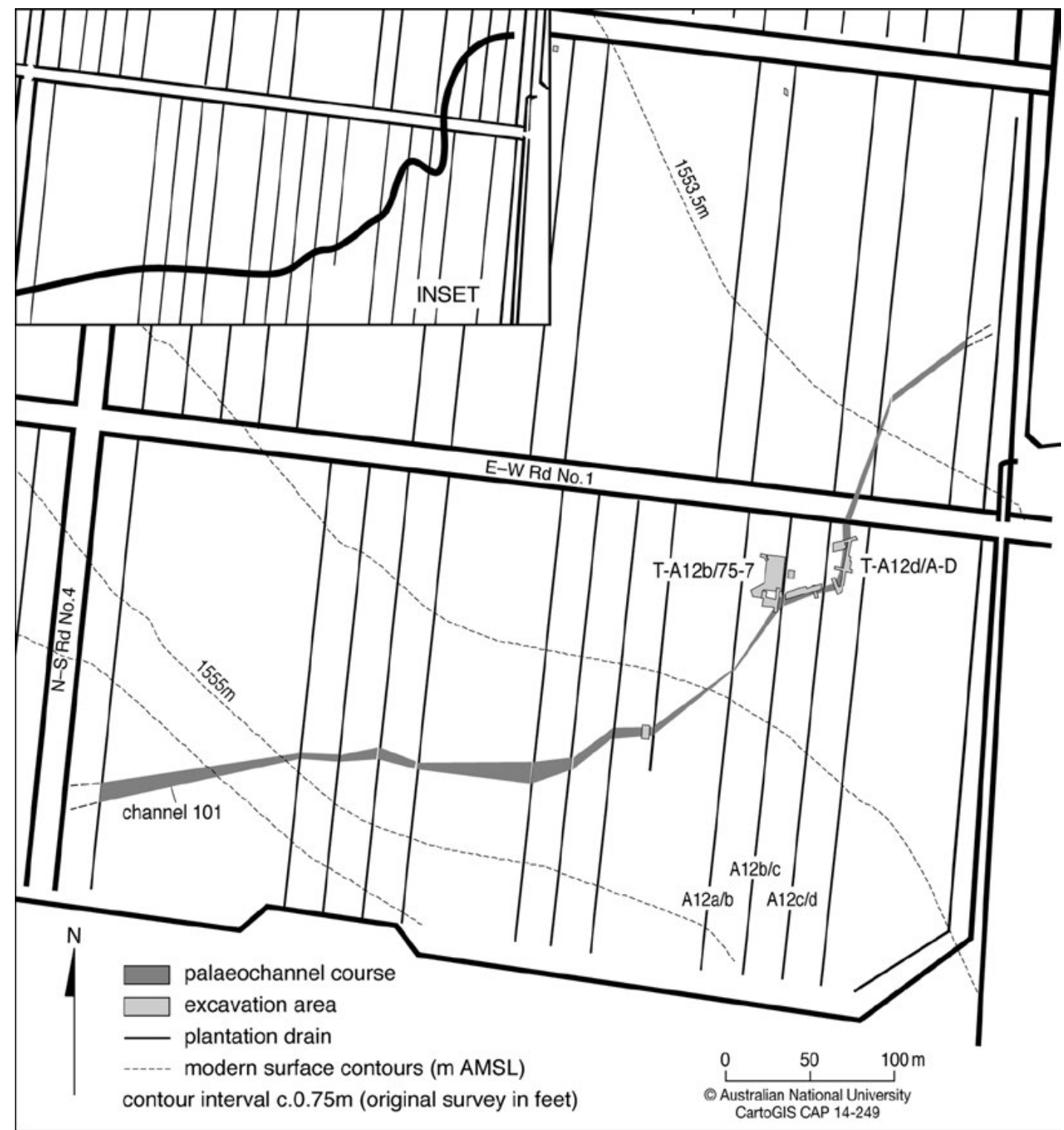

Figure 11.1 Plan of the SE corner of Kuk Station showing the location of excavations beneath grey clay, the course of channel 101 (Kundil's Baret) and some isolated features.

The course of channel 101 is reconstructed from bank widths recorded in the walls of Station drains and excavation trenches that cross it.

Source: Denham, Golson and Hughes (2004: Fig. 4). Drawing by Jennifer Sheehan, CartoGIS Services, College of Asia and the Pacific, ANU. The inset plan depicts a previously published course for the channel. Source: Golson (1977a: Fig. 2). Reproduced with permission. 


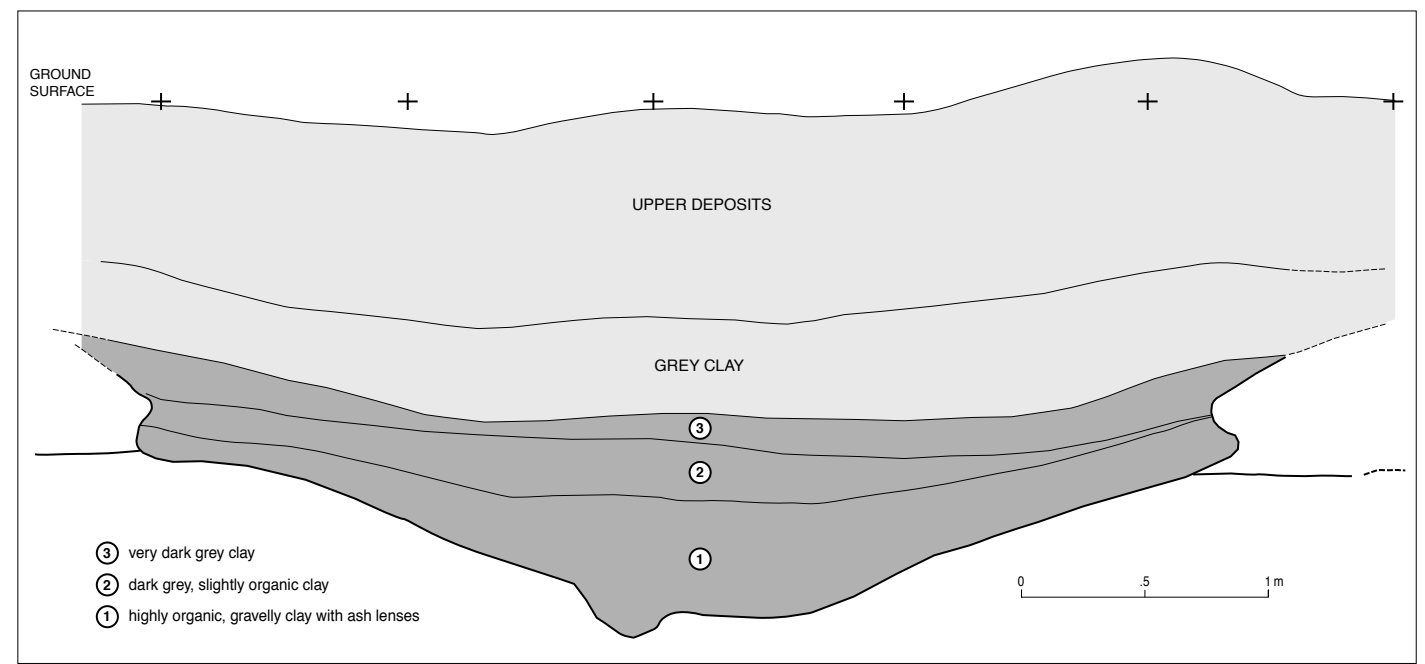

Figure 11.2 A typical cross-section of channel 101 showing its shallow depth, gently concave base and slightly undercut banks.

Source: Denham (2004: Fig. 5), reproduced with permission.

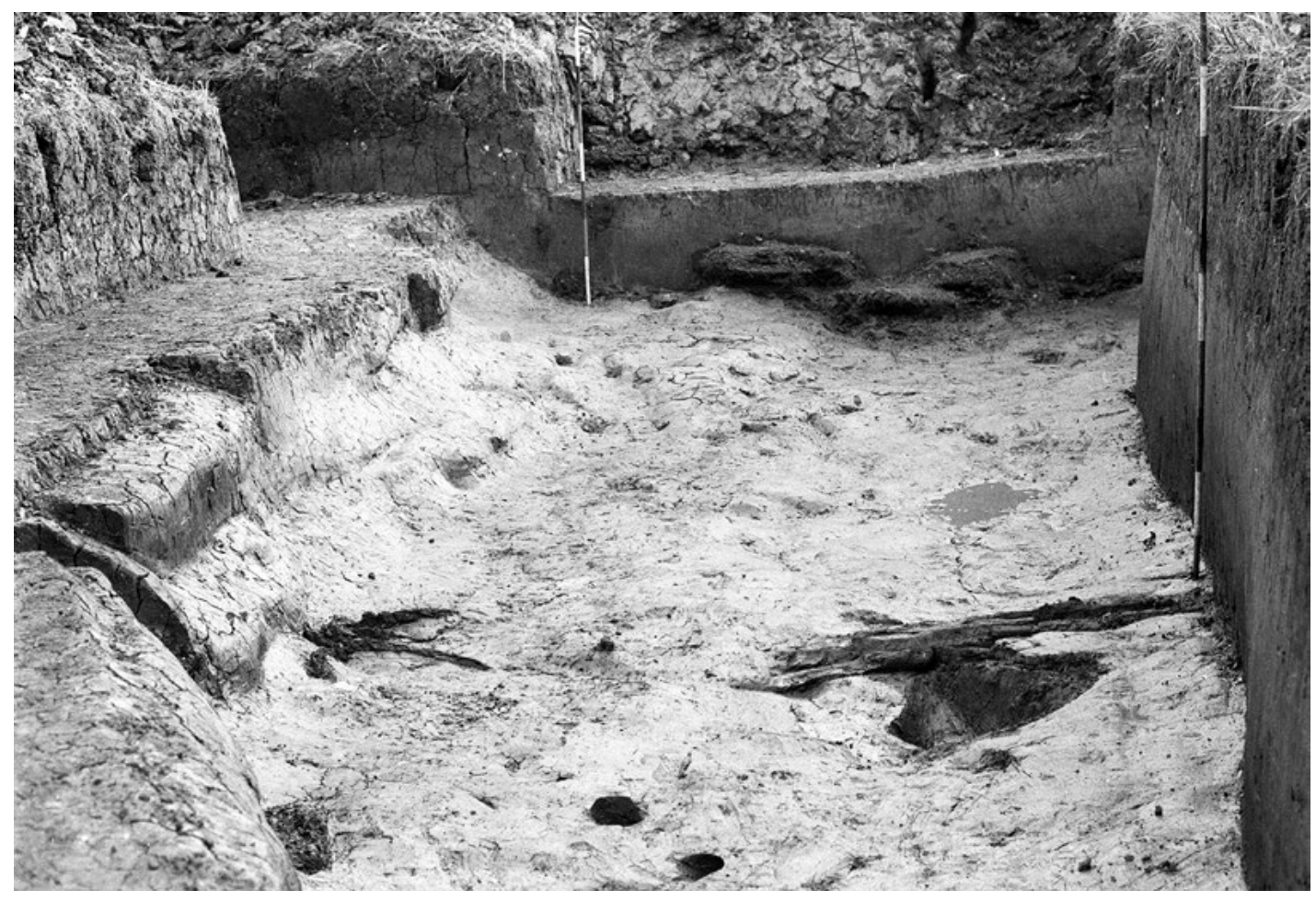

Figure 11.3 Looking south along the bed and east bank of channel 101 after excavation at the north end of block A12d in 1975 (see Fig. 11.1).

Note one ranging pole to the south, at the E-W cross-section through channel fill, and another to the west at the N-S longitudinal section. Both are graduated at $200 \mathrm{~mm}$ intervals.

Source: Photograph by Klim Gollan, Kuk archive, 1975. 


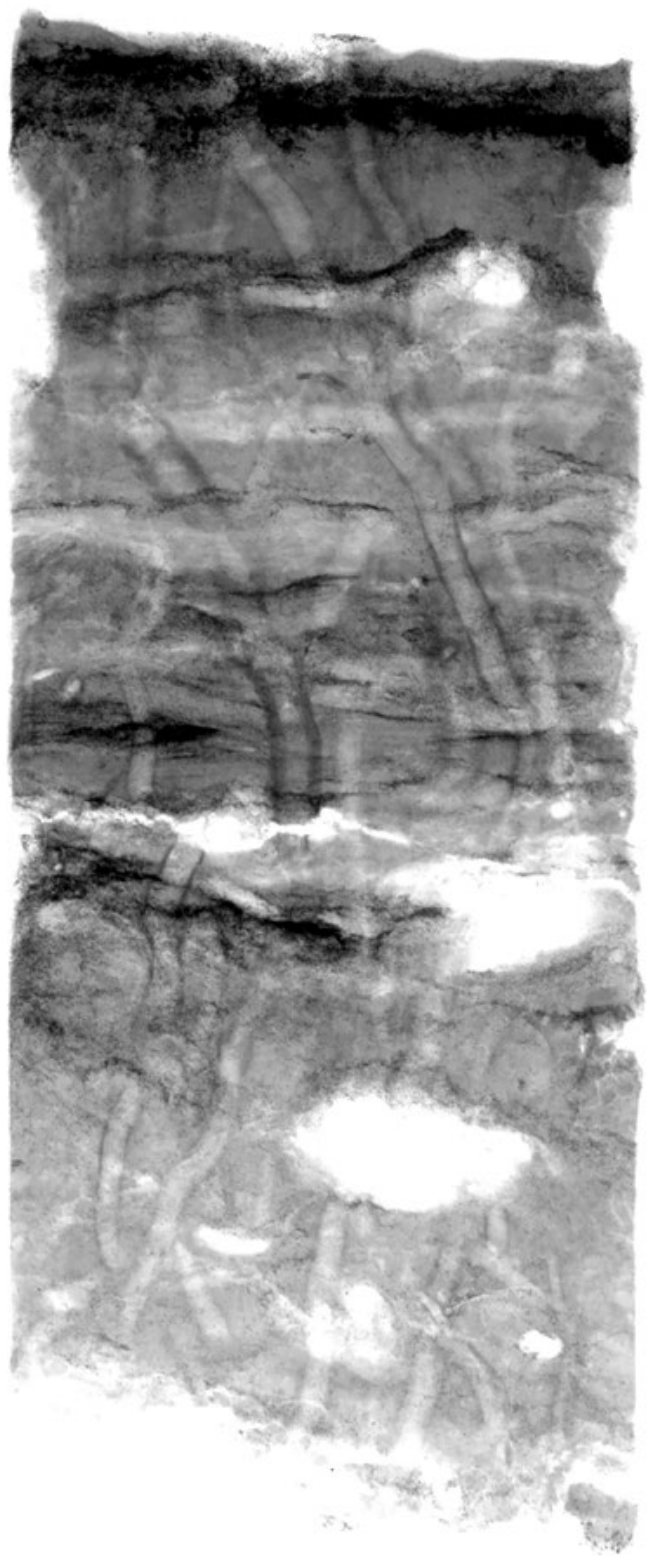

Figure $11.4 \mathrm{X}$-radiographic image showing the preservation of original sedimentary stratification, or banding, within the basal fill of channel 101.

The lighter vertically inclined lines that cut across the horizontal banding are root channels and faunal burrows (i.e. made by worms and beetles), which formed postdepositionally during a short drier period after the period of initial sedimentation.

Source: Denham, Haberle and Pierret (2009: Fig. 2b), reproduced with permission.
Archaeologists and geomorphologists who have worked at Kuk disagree about whether channel 101 was made by people (proposed by Philip Hughes) or is a natural watercourse (proposed by Tim Denham). Different lines of evidence have been marshalled to support different interpretations. For example, there is some debate about whether the palaeochannel cut a course through low rises on the wetland edge; a natural watercourse would not be expected to cut a course through a low hillock, but would ordinarily pass around its base. Although present-day topography suggests the channel passed through higher ground, there is debate among the authors as to whether this low rise existed 10,000 years ago and whether channel 101 followed a preexisting depression through it (respectively Golson 1991b: 485 and Denham 2003a: 126-146, 2004: 49-53; see Denham, Golson and Hughes 2004: 269274 for a review). Similarly, features exposed by excavation on the banks could have resulted from human activity or been a product of stream flow around woody debris in the channel, tree-throw or slumping.

Whether the channel was directly dug or modified by people is debatable. Irrespective of its mode of formation, the channel appears to have been short-lived and rapidly filled with materials eroded from the catchment and at the wetland edge following human-induced forest clearance (as discussed below). The open channel would have lowered water tables along the wetland edge, thereby making adjacent palaeosurfaces suitable for plant exploitation practices. A stone pestle recovered from the basal fill of the channel indicates that 10,000 years ago people at Kuk were processing starchrich food plants, perhaps grown adjacent to the channel. This pestle (K/75/S178) was used to prepare a yam tuber (Dioscorea sp.) for consumption (Fullagar et al. 2006: 601-602, Fig. 10; see Chapter 20, section 'Phase 1' and Textbox 10.3). 


\section{Palaeosurface}

On the land surface adjacent to the palaeochannel are pits, runnels, stakeholes and postholes, with associated artefacts and evidence of limited soil formation (Figs 11.5-11.8). The features are cut into black organic clay, which probably provided the topsoil at the time, and are filled by grey clay. They do not have a regular pattern or design, although some pits are associated with postholes and stakeholes. The human origin of the features is interpreted from their morphology, inferred function, nature of fills and other associations. Taking multiple lines of evidence together, the palaeosurface is considered representative of a former plot used for the cultivation of edible plants.
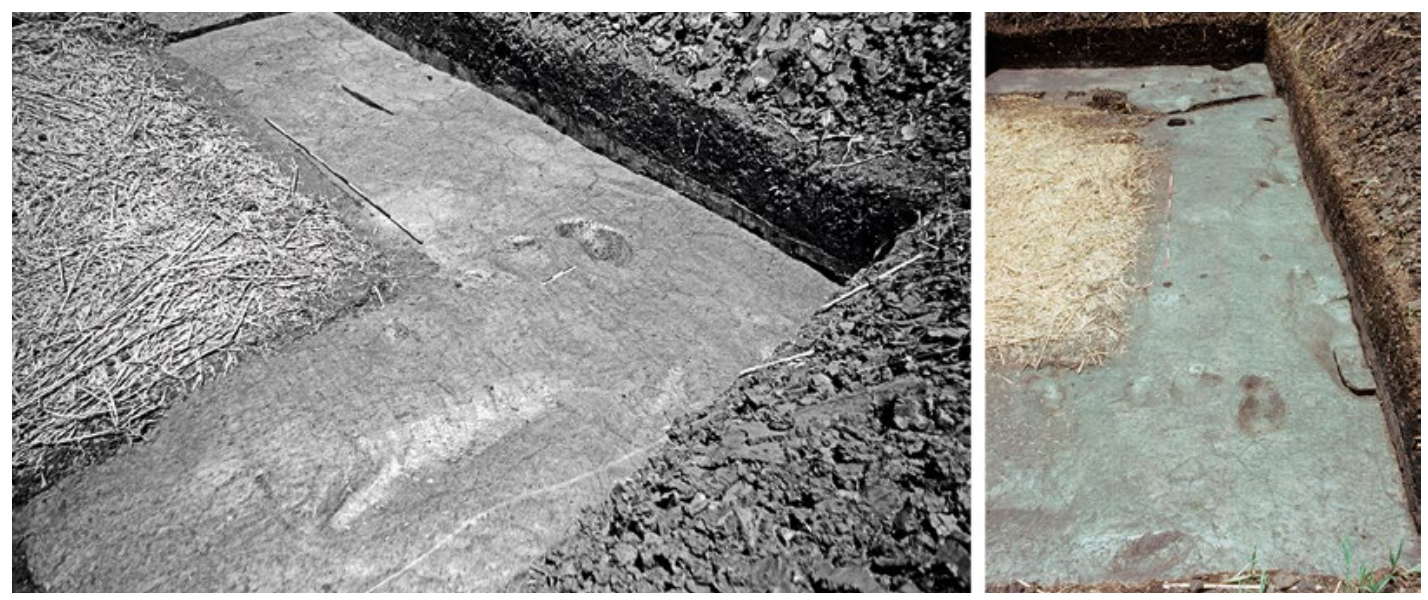

Figure 11.5 Left image shows the base of a 1976 excavation trench in block A12b after the removal of grey clay, revealing Phase 1 features dug into the surface beneath. The image shows the view SW, with some archaeological features fully excavated and others with their fills of grey clay still to be removed. Right image shows the view to the south, with all features fully excavated, revealing pits, basins, stakeholes and the like thought to represent the planting, staking and harvesting of plants. The area in the lower half of this photograph appears in Figure 11.7 as an elevated location between two areas of elongated depressions, $B$ and $C$, at the northern end of the excavation. The ranging pole is graduated at $200 \mathrm{~mm}$ intervals.

Source: Photographs by Alistair Marshall, Kuk archive, 1976.

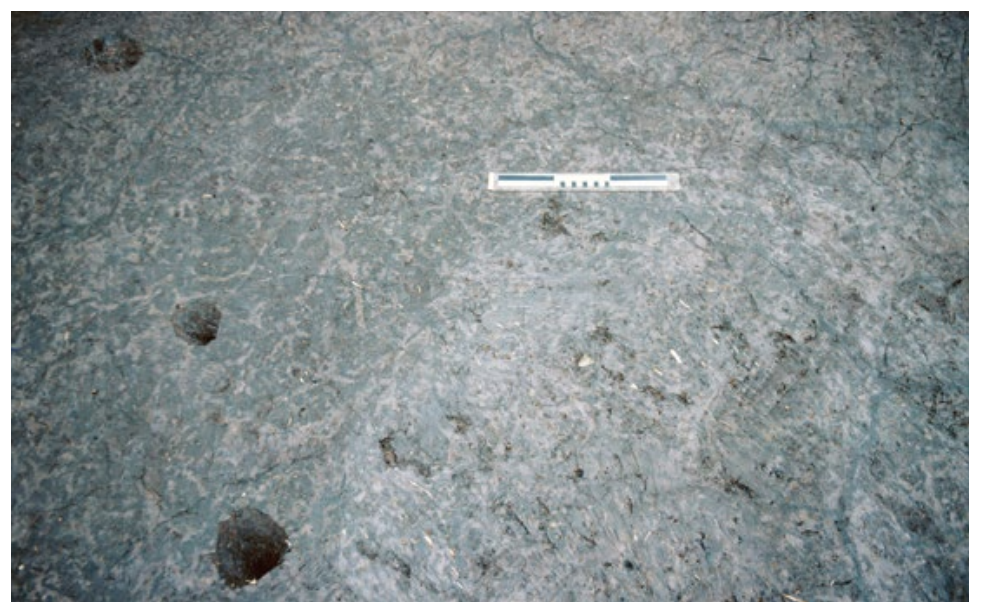

Figure $11.6 \mathrm{~A}$ close-up of the saucer-like feature immediately north of the two easterly stake holes in the line of three across the middle of Figure 11.5b.

In it is shown a chert flake (K/76/S28) found during excavation underneath the grey clay fill and discussed in Chapter 20 . The scale is graduated at $100 \mathrm{~mm}$ intervals.

Source: Photograph by Alistair Marshall, Kuk archive, 1976. 


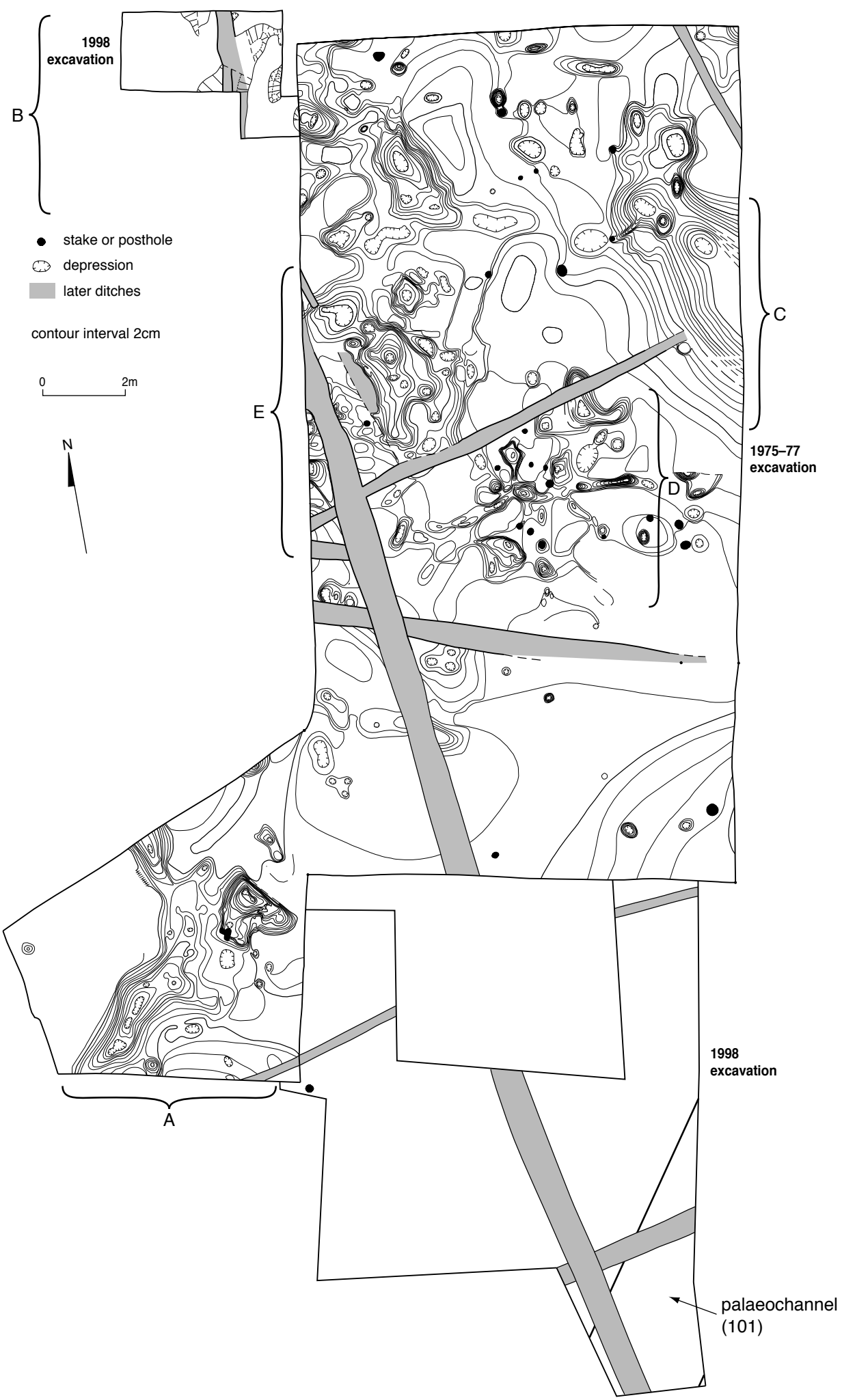

Figure 11.7 Composite base plan of the Phase 1 palaeosurface exposed in excavations in block A12b undertaken in 1975-77 and in 1998.

The features have been grouped into five complexes: three composite curvilinear or sinuous runnels ( $A, B$ and $C$ ) and two locations comprising upraised areas formed by surrounding intersecting depressions ( $D$ and $E$ ).

Source: Denham, Golson and Hughes (2004: Fig. 9) modified from Denham (2004: Fig. 7). Reproduced with permission. 


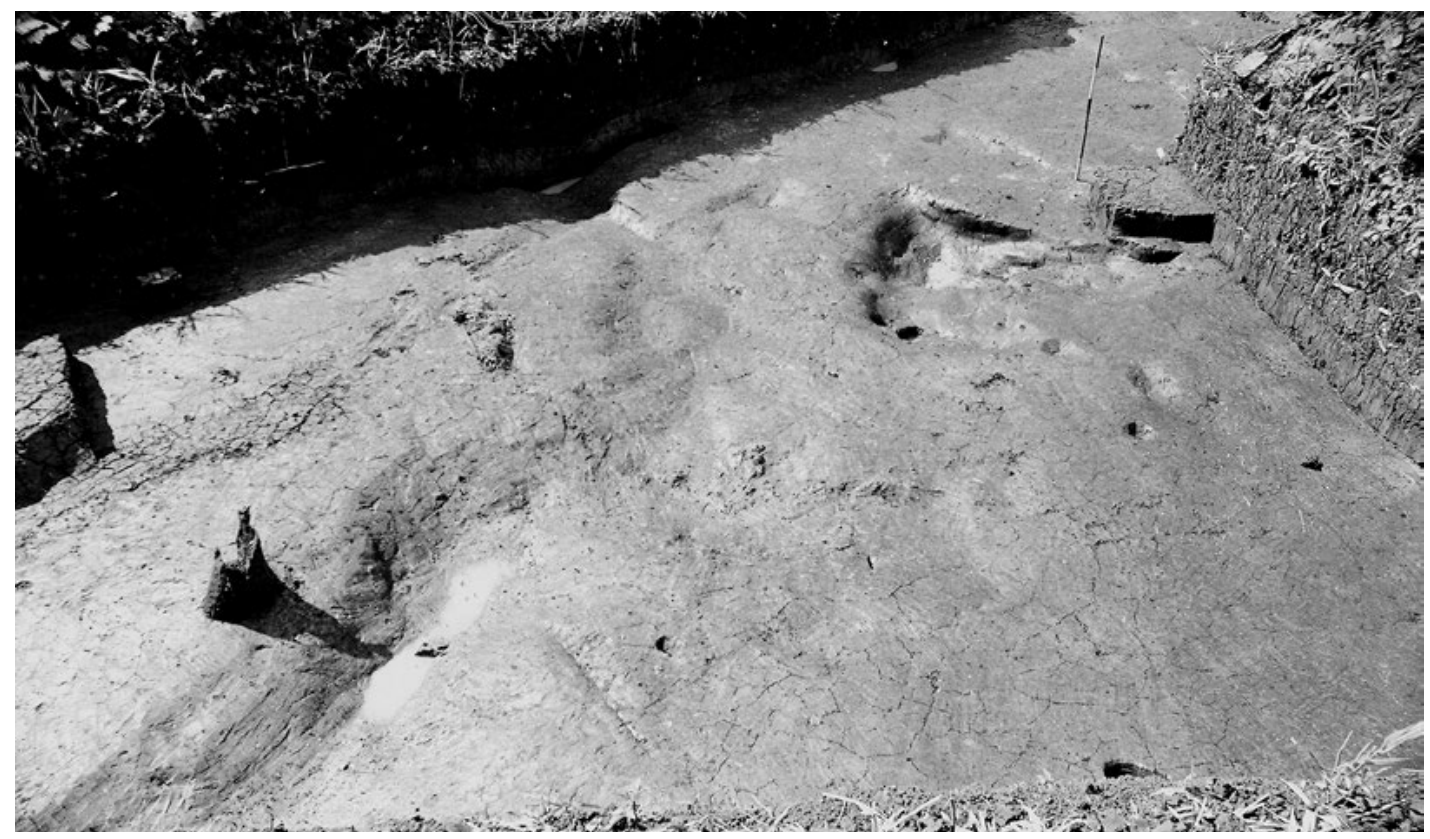

Figure 11.8 A view NE over complex A (of Figure 11.7) after its excavation in 1977, showing the character of the archaeological remains.

Source: Photograph by Ed Harris, Kuk archive, 1977.
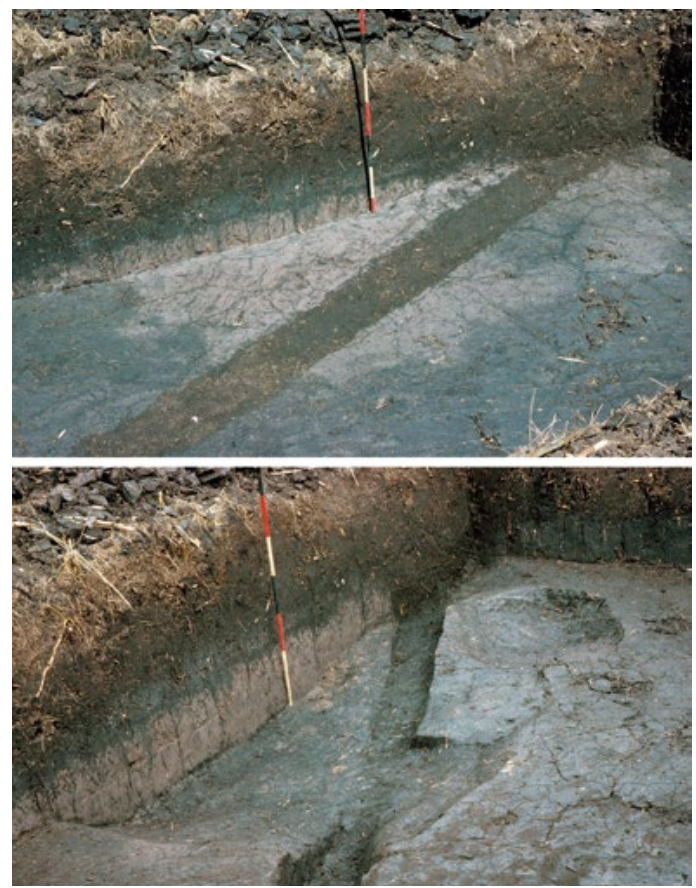

Figure 11.9 Top image is a view of the base of an excavation trench of 1975 at the northern end of block A12c: a grey clay-filled feature with a Phase 5 garden ditch crossing it from WSW to ENE. Bottom image taken after excavation of the feature, which appears as a complex of intersecting basins.

Source: Photographs by Klim Gollan, Kuk archive, 1975.
First, the edges of many features are smooth and clearly defined against underlying strata (Figs 11.9a and 11.9b), particularly Ep and Rom ashes (Fig. 11.10). Consequently, these often shallow features are not products of clay deformation or peat shrinkage. Edge definition and smoothness are suggestive of dug features rather than of tree bowls, root moulds and tree-throw depressions, which would be anticipated to have more irregular edges. In the context of the limited Papua New Guinea archaeological database at the time of the Kuk investigations, it was initially suggested that such basins might have been pig wallows, given their similarity to depressions in Phase 2 accompanied by stakeholes, although this interpretation has long since been discounted (Denham, Golson and Hughes 2004: 277; and cf. Fig. 12.10). 


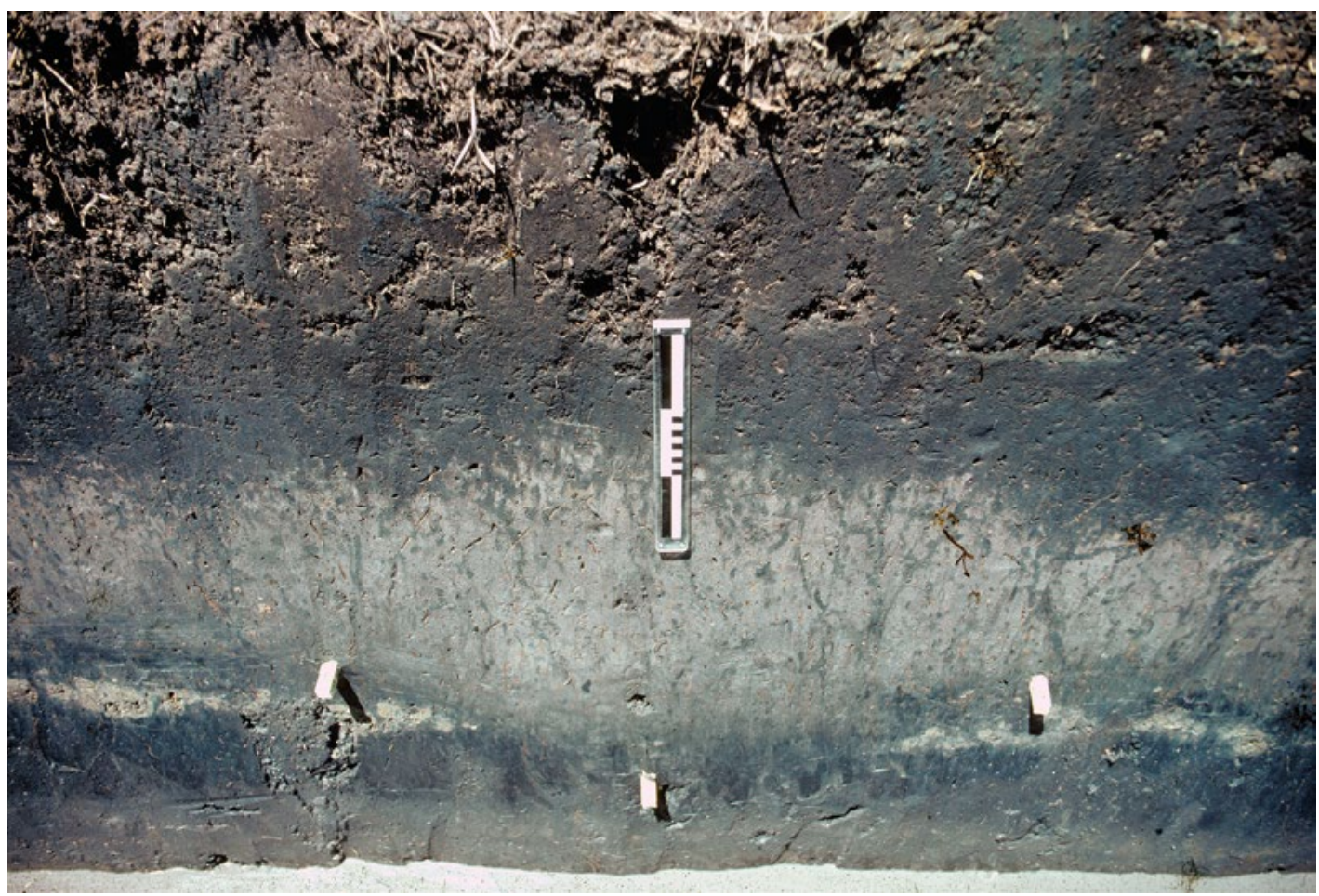

Figure $11.10 \mathrm{~A}$ basin-shaped feature buried under grey clay in the west wall of Station drain A12a/b, which was dug in 1976.

Note how the feature cuts across and is clearly defined against an underlying exposure of Ep ash that is preserved as a lens of indurated nodules.

Source: Photograph by Alistair Marshall, Kuk archive, 1976.

Second, runnels and pits are interpreted to represent the wet cultivation and harvesting of taro (Colocasia esculenta), respectively. These features did not form an integrated drainage network as described for areas of the Phase 2 palaeosurface in Chapter 12. Pits and runnels would have been wetter than adjacent areas and such conditions are favourable to the growth of Colocasia taro (cf. Fig. 11.11). Smaller pits within larger features and irregularly shaped pits may represent the digging of taro corms (after Powell et al. 1975: 11-12 and Tim Bayliss-Smith, pers. comm., 2006).

Third, Colocasia taro is known to have been in the vicinity and used by people during Phase 1 because aroid seeds have been collected from the fills of channel 101 (see Textbox 10.1) and starch grains have been identified on the used edge of a stone flake (K/76/S29B) collected from the palaeosurface (Fullagar et al. 2006: 605; see also Table 10.T3.1 and Chapter 18). Processing of taro is necessary to remove bitter-tasting oxalates, to enhance taste and to liberate nutrients for digestion. The few stone artefacts present on this palaeosurface are of the kind to be expected within a subsistence plot and represent the use of stone tools to process plants prior to cooking. At this time, most artefacts used for gardening and food processing were probably wooden and have not been preserved in palaeosurface features.

Fourth, numerous postholes and stakeholes occur on the palaeosurface and seem to be associated with pits (Figure 11.12). In gardens in the Kuk vicinity today, posts and stakes are used to support crops such as species of cane grass (e.g. Setaria palmifolia) and Musa bananas (after Powell et al. 1975: 4-12; Gorecki 1982: 203-210; see Figs 12.12-12.13), some of which were present in the Kuk vicinity at least 10,000 years ago (see Table 10.1). 
Fifth, the basal fills of features on the palaeosurface are more heterogeneous than underlying (black organic clay) and overlying (grey clay) strata (Fig. 11.13). Although only a coarse guide, this heterogeneity is interpreted as representing limited soil formation on black organic clay when it was exposed at the surface during Phase 1 . The soil profile is characteristic of immature soils in alluvial and wetland settings that do not generally have long periods to form before being buried or waterlogged. Limited mechanical admixture plausibly reflects minimal tillage techniques, such as dibbling during planting and/or digging during harvesting.

Sixth, elevated charcoal densities in the fill of one palaeosurface feature could indicate localised burning within the plot. Burning occurs prior to planting in plots across New Guinea today, although the case in question may have been associated with other activities, e.g. hunting or a temporary rest site.

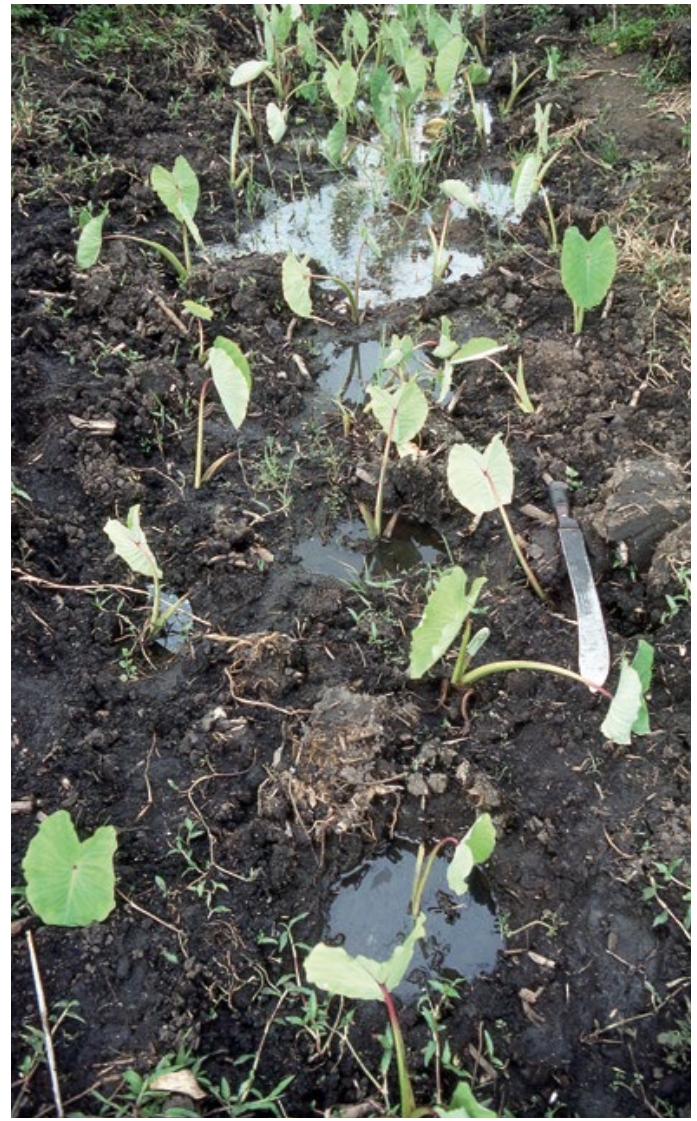

Figure 11.11 Taro growing in wet conditions along an in-filled drain at a garden near Mt Ambra.

Source: Photograph by Alistair Marshall, Kuk archive, 1976.

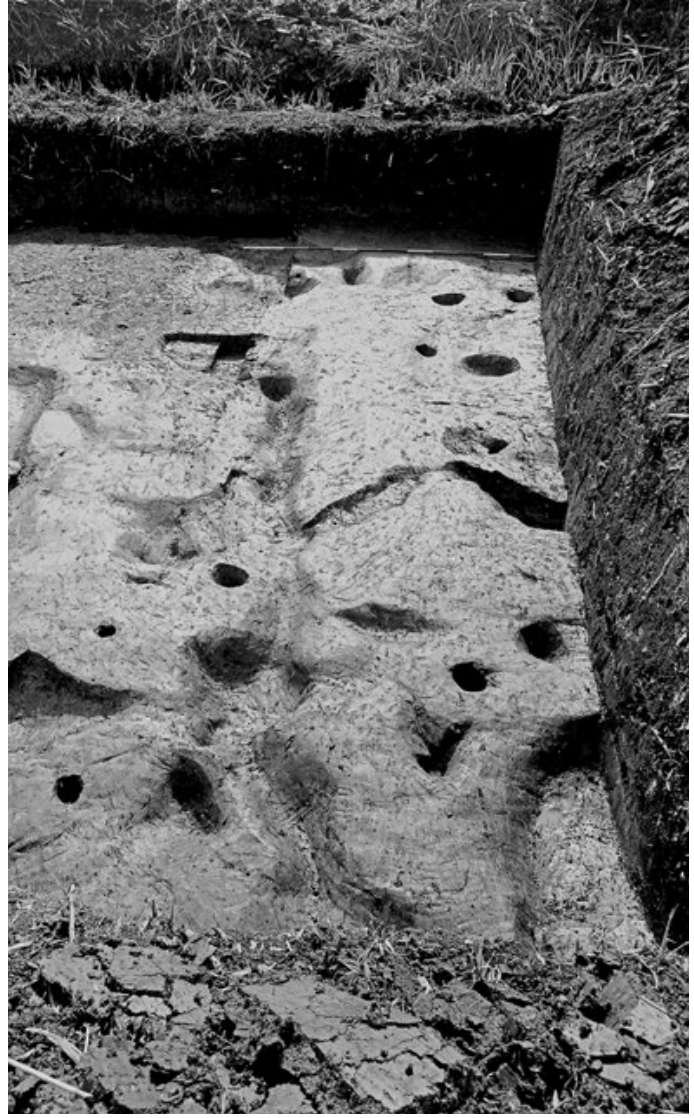

Figure 11.12 Looking east over part of the Phase 1 palaeosurface excavated in 1976, showing the juxtaposition of various feature types, particularly microtopographic drainage features and stakeholes.

The area in the photograph is part of complex $D$ in Figure 11.7. It can be identified in Figure 11.7 by the group of four features, two stakeholes to the right of the lower bracket of D, one stakehole and one small pit to the left of the bracket. Note that the triangular depression to the right of the upper case $\mathrm{D}$ on Figure 11.7 is a later disturbance. The ranging pole is graduated at $200 \mathrm{~mm}$ intervals.

Source: Photograph by Alistair Marshall, Kuk archive, 1976. 

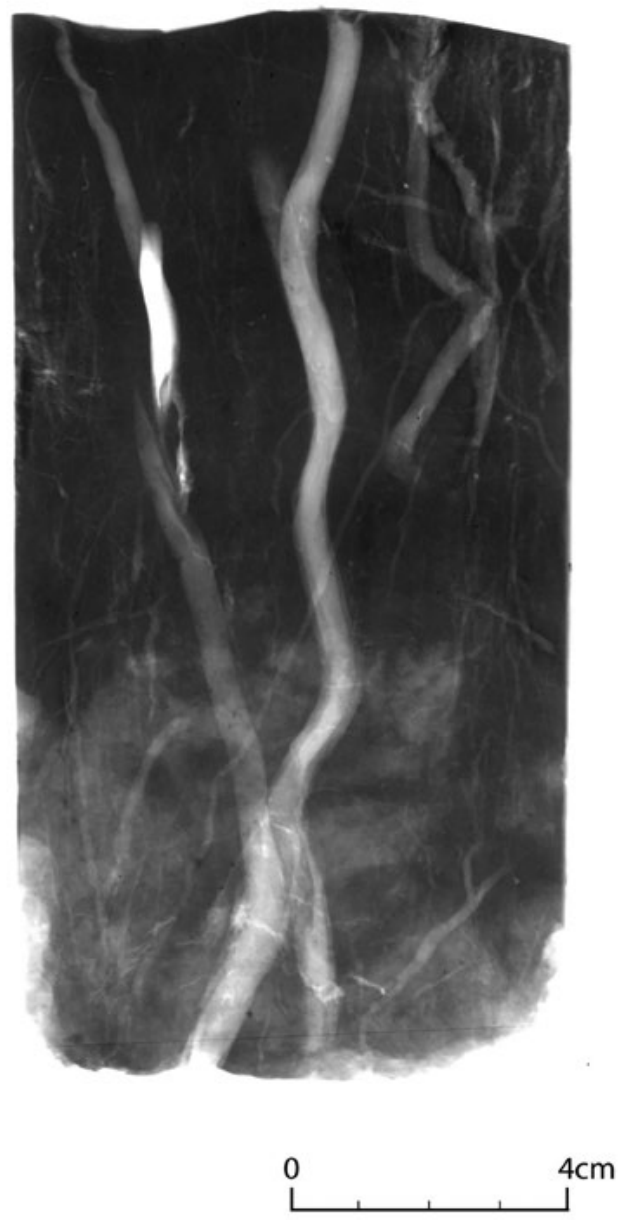

Figure $11.13 \mathrm{X}$-radiographic image showing soil formation at the base of a Phase 1 feature.

Soil formation is evident from the slightly less dense aggregates (lighter patches in the lower third of the image), which are clearly discernible against the overlying darker and denser grey clay fill.

Source: Denham, Haberle and Pierret (2009: Fig. 2a), reproduced with permission.
In summary, the multidisciplinary evidence for the Phase 1 palaeosurface is consistent with clearance, cultivation, digging and staking within a plot. The plot was probably inter-cropped, i.e. different plants were grown together within the plot. Colocasia taro was used and a range of other edible and starch-rich plants were present in the vicinity, including edible cane grass (e.g. Setaria palmifolia), Musa bananas, gingers (Zingiberaceae) and a yam (Dioscorea sp.). A range of vegetables (Coleus sp., Oenanthe javanica and Solanum sp.), berries (Rubus spp.) and nut-bearing trees (Castanopsis sp., Pandanus spp.) were also present and potentially used.

Palaeosurface features appear to be restricted in distribution to an area of higher ground adjacent to the palaeochannel. The use of this area of higher ground seems to have been short-lived, occurring during the period when channel 101 was open. Following the abandonment of the channel, which filled in rapidly with debris and sediment eroding from the catchment, a reversion to wetter conditions and burial under grey clay prevented further human modification of the palaeosurface, retarded subsequent soil formation and aided preservation of the archaeological remains. Occasional reuse within the plot probably occurred to harvest wild plants or cultivated ones surviving within the abandoned plot, e.g. Colocasia taro and Musa bananas. Similar practices of harvesting Musa bananas and other crops in abandoned gardens are common throughout New Guinea today.

\section{Landuse}

Several lines of on-site and off-site evidence indicate that people were manipulating their environment in the Kuk catchment and on the wetland edge 10,000 years ago. Materials deposited within channel 101 reflect human alteration of the environment at both local and regional scales. The presence of delicate materials such as soil aggregates and leaves, as well as coarse organic materials such as branches, are suggestive of a local origin. Delicate aggregates and organic materials would not be expected to survive extended periods of transportation in a small stream. The presence of these materials together with large blocks of wood is consistent with the clearing of vegetation and resultant soil erosion on land immediately adjacent to channel 101. Such an interpretation is supported by high charcoal frequencies in these fills as well as in that of one adjacent palaeosurface feature (Denham et al. 2003; Denham, Sniderman et al. 2009; Haberle et al. 2012). 
The fills of channel 101 are suggestive of extensive human activities in the stream's catchment. Deposition of grey clay in the palaeochannel and on the palaeosurface over the period 10,000 to 7000 years ago has been interpreted to be a result of erosion following forest clearance for dryland cultivation under a swiddening regime (Golson and Hughes 1980; Hughes, Sullivan and Yok 1991). Recent palaeoecological research has shown the role of fire in that clearance (Denham et al. 2003; Denham, Haberle and Lentfer 2004; Denham and Haberle 2008; Denham, Sniderman et al. 2009). Sediments, pollen, macrobotanical remains and charcoal in channel 101 reflect increased local disturbance using fire. High pulses of charcoal represent an increased intensity of fires within the catchment in contrast to Late Pleistocene records (see Chapter 9). Increasing frequency of fires (measured from microscopic charcoal) is accompanied by decreasing frequencies of primary forest taxa and increasing frequencies of disturbed, secondary and grassland taxa (measured from pollen). Disturbance of the primary forest occurred at a time when there is no clear evidence that forests were under climatic stress (cf. Brookfield 1989), which would have sensitised them to disturbance. Sustained and cumulative disturbance accompanied by fire indicates human as opposed to climatic causes (after Haberle 1994). In the highlands context, these signatures are interpreted as representing extensive swidden cultivation of slash-and-burn or slash-and-mulch types (cf. Haberle 2003). Smaller-scale house-garden horticulture is less likely to result in a cumulative and prolonged signal of forest disturbance (cf. Harris 1995: 853; 1996b: 568). Similarly, the palaeoecological signals under discussion are not consistent with anthropogenic exploitation of patches within the forest caused by landslides, lightning, treethrow and other natural phenomena.

While the antiquity of the archaeological and palaeoecological records is unique to Kuk, they are not likely to have been restricted to the site or its catchment. Evidence for the extent of regional forest clearance by the mid Holocene is provided by three sites in the upper Wahgi Valley in addition to Kuk: Draepi-Minjigina, Lake Ambra and the Manton site on Warrawau Tea Estate (Powell 1982a: 218-221, 223; see Fig. 9.1 Inset here). Although the timing of initial forest clearance at these sites is unknown, the Kuk evidence suggests that it occurred in the early rather than the mid Holocene (Denham, Haberle and Lentfer 2004; Denham and Haberle 2008). Similar forest disturbance was initiated in the Baliem Valley of Indonesian New Guinea before 7800 years ago (Haberle, Hope and de Fretes 1991).

Although dryland practices continued in the catchment at Kuk after 10,000 years ago, there is no archaeological evidence for continued use of the wetland margin during the next 3000 years. There was a gradual succession from wetter (typha reed and pandanus swamp forest) to drier (Compositae, ferns and forest regrowth) conditions locally on the swamp margin, with an increasingly deforested dryland landscape in the catchments. Intact chains of phytoliths within the grey clay indicate that Musa bananas were growing in the vicinity. Diagnostic seed phytoliths of Musa (formerly Eumusa) section bananas are present with the onset of grey clay deposition (see Textbox 10.2). A stone mortar fragment (K/77/S34) collected from within grey clay (Golson 2000, Fig. 11.14 here; see also Chapter 18) is suggestive of people processing plants, like nuts of Castanopsis and Elaeocarpus, seeds of Job's tears (Coix lachryma-jobi) (Bulmer and Bulmer 1964: 70; R. Bulmer 1964), or Colocasia taro, as Swadling has argued (1983: 74-75; cf. Swadling and Hide 2005: 295-296). This item belongs to the well known but less well understood stone mortar complex of New Guinea, few examples of which have been found in datable contexts. The find spot at Kuk is conservatively dated to around 7500-7000 years ago, which makes it the oldest specimen on record from New Guinea (Golson 2000: 236). 

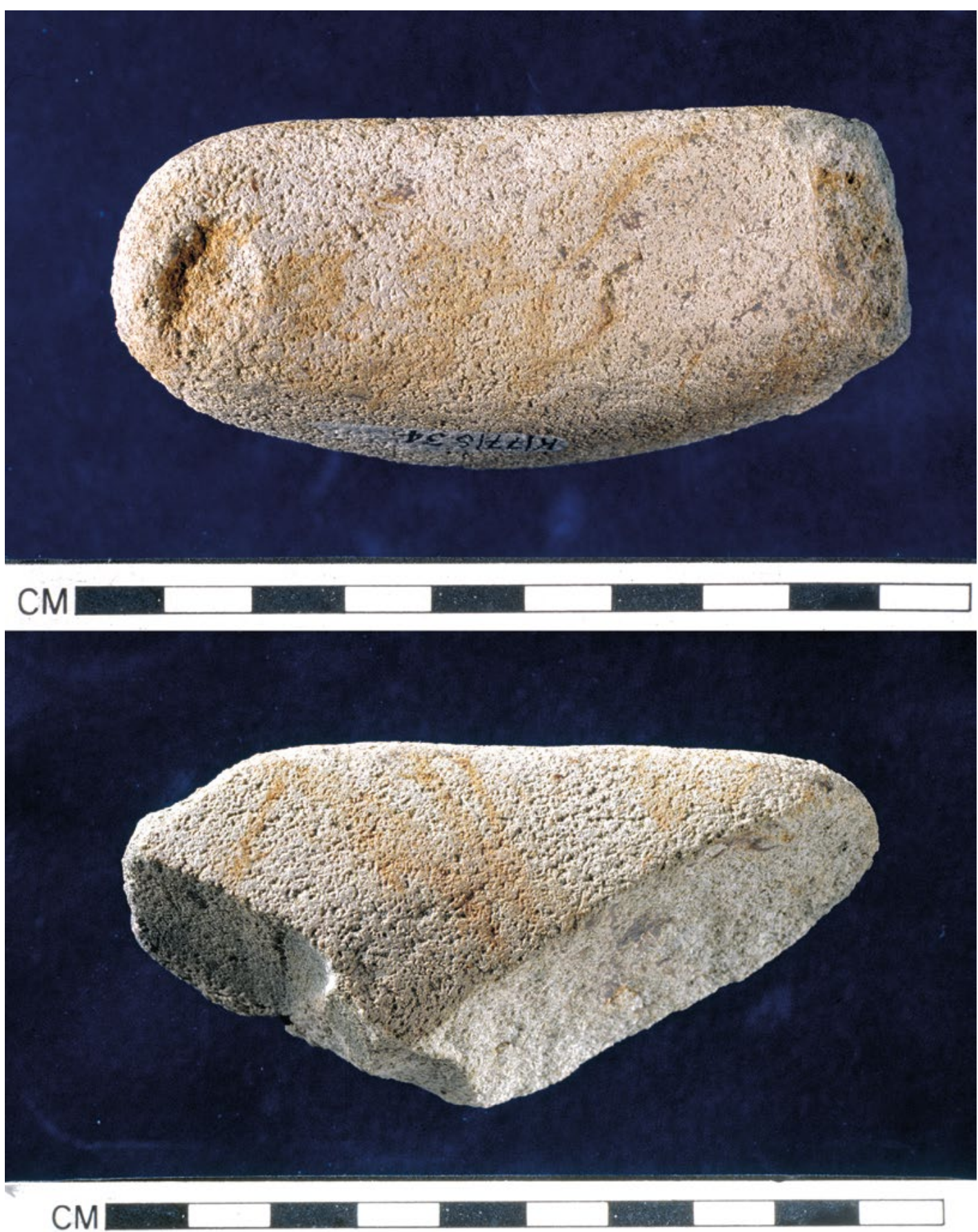

Figure 11.14 The rim fragment of a stone mortar found in the grey clay fill of a Phase 1 basin, above its base, during excavation in 1977.

The Phase 1 basin in question is the one protruding east from beneath the west wall of the 1976 excavation, which is in the foreground of Figure 11.5b. It was fully exposed in 1977 when the trench wall was moved back and forms part of complex B, which Denham defined after his 1998 excavation (see Fig. 11.7). Figure 11.14 (top) looking down at the outside of the vessel, with the lip at the top and the shoulder below. Figure 11.14 (bottom) looking at the inside of the rim with the lip at the top. Source: Photographs by Bob Cooper and Darren Boyd; cf. Golson (2000: Plate 1a and 1b). 


\section{Agriculture at 10,000 years ago?}

In the context of continuing dryland cultivation, Phase 1 is a short-lived period of activity in the Kuk Swamp around 10,000 years ago. The spatial extent and chronology of plant exploitation practices elsewhere in New Guinea during the early Holocene remain to be determined. Before this can be undertaken, better resolution is needed in translating generalised palaeoecological signals into specific prehistoric practices (cf. Haberle 2003; Powell 1970a; Denham 2007a; Denham and Haberle 2008). Even with high-resolution palaeoecological indicators, prehistoric subsistence is best inferred following the excavation of the physical evidence of former practices, which are best preserved along wetland margins.

Both on-site and off-site records at Kuk indicate localised and patchwork forest clearance within the catchment using fire, which led to increased erosion rates. Archaeological traces of prehistoric dryland practices are prone to destruction by subsequent erosion, gardening and soil formation, whereas the morphology of the constituent features on the wetland edge has been preserved by burial and waterlogging.

The authors differ about the interpretation of the Phase 1 evidence (Denham, Golson and Hughes 2004: 278, 293). For Hughes and Golson (drawing on Golson and Hughes 1980), channel 101 is artificial, dug to allow the cultivation of the wetland margin, as represented by the features on the Phase 1 palaeosurface. For them, Phase 1 was similar to Phases 2-6 at Kuk, that is, 'wetland management for cultivation' (Hope and Golson 1995: 824) associated with dryland gardening in the swamp catchments. In their view, the appearance of these practices at Kuk 10,000 years ago represents new developments in both the dryland and wetland spheres, shifting cultivation in the former and drained cultivation in the latter. These developments are 'new' in the wider context of highlands prehistory because they contrast with Late Pleistocene evidence for forest disturbance (Golson 1991a: 84-88).

On the basis of archaeological, palaeoecological and sedimentological evidence produced by his more recent research (Denham et al. 2003; Denham 2003a, 2004), Denham questions these interpretations. He sees channel 101 as a natural channel that was not modified to any great extent by people. In his view, the Phase 1 palaeosurface at Kuk represents some form of plant exploitation on a wetland margin, not as a separate sphere, but rather as consistent with the spatial extension of dryland practices onto the swamp margin, perhaps during short-lived, locally drier conditions. Dryland practices may have been modified for the wetland edge, for example for the cultivation or exploitation of Colocasia taro.

Even though specific interpretations vary, all three authors agree that the multidisciplinary evidence for Phase 1 at Kuk represents prehistoric plant exploitation. The archaeological remains, archaeobotanical finds and palaeoecological signals can all be interpreted with reference to contemporary forms of plant exploitation in New Guinea. For Golson and Hughes, the drainage and modification of the wetland margin signify the emergence of wetland agriculture, potentially focused on Colocasia taro. This interpretation is based on the nature of the archaeological remains at Kuk and was proposed before macrobotanical and microfossil evidence of Colocasia taro had been found. For Denham, the evidence indicates practices similar in nature (on-site archaeological evidence) and environmental impact (off-site palaeoecological evidence) to extensive forms of plant exploitation, or potentially swidden cultivation. At this time, there may have been no great differences in the way people exploited drylands and wetlands, although different plants may have been present and targeted in each environment. People may have begun to focus on starch-rich edible plants, such as Musa bananas on drier slopes and Colocasia taro in wetter environments, which is characteristic of present-day agriculture across New Guinea. 
The absence of archaeological remains at Kuk and other wetland sites in the highlands over the subsequent 3000 years prevents a greater understanding of the diversity and development of subsistence practices in dryland and wetland environments. Palaeoecological signals indicating forest disturbance using fire, similar to those documented during Phase 1 at Kuk, continue from the early to mid Holocene and are accompanied by increased deposition of grey clay on the wetland margin suggestive of increased erosion in the catchment. It is not until the advent of mounded cultivation on the wetland margin at 7000-6500 years ago that clearly intensive forms of cultivation are present. 
This text is taken from Ten Thousand Years of Cultivation at Kuk Swamp in the Highlands of Papua New Guinea, edited by Jack Golson, Tim Denham, Philip Hughes, Pamela Swadling and John Muke, published 2017 by ANU Press, The Australian National University, Canberra, Australia. 